\title{
Chinese Poor Social and Economic Transformation in Bangka (An Overview Between Stigma and Reality)
}

\author{
Sandy Pratama ${ }^{1}$, Rini Archda Saputri ${ }^{2}$, Ranto $^{3}$ and Ibrahim ${ }^{4}$ \\ \{sandy_djarib@yahoo.co.id ${ }^{1}$, riniardhasaputri@gmail.com ${ }^{2}$, rantopalempat@gmail.com ${ }^{3}$, \\ iim_babel@yahoo.com ${ }^{4}$ \} \\ Department of Political Sciences, Bangka Belitung University, Bangka, Indonesia ${ }^{1234}$
}

\begin{abstract}
There are many main academic studies that focus on identity politics raising about the dynamics of the existence of ethnic Chinese in Indonesia. Previous studies dominated the issue of discrimination and social, economic, political and cultural intimidation experienced by this group in the trajectory of Indonesian history. This study tried to fill the gap in the study of the phenomenon of poor Chinese who became the antithesis of the stigma of their elitism both socially and economically. By using a qualitative approach, this research attempts to describe the picture of poverty and why factors for the Bangka case are found in poor ethnic Chinese communities. The study found that historiography of the origins of Chinese migrants in the past still influenced the process of cultural socio-economic transformation that would shape them to become rich or poor. In general, structural poverty factors such as the availability of employment, educational orientation and competitiveness, the sensitivity of government policies and the perspective on modernism have a significant influence on the economic capabilities of the poor Bangka Chinese ethnic.
\end{abstract}

Keywords: poor Chinese people, structural poverty, socio-economic transformation

\section{Introduction}

Chinese life in Indonesia is always interesting to study. Especially regarding its socioeconomic existence in Indonesia. Even so, his presence cannot just be generalized. This is because the Chinese who come to the archipelago originate from different variants and the complex where they come from is a multicultural and culturally diverse society. So actually, Chinese who are scattered throughout Indonesia are a group of people who have been far apart from their cultural parents in mainland China. They have formed a new culture in the form of a mixture that occurs due to the process of acculturation that has been going on for tens or even hundreds of generations [1].

There is a stigma attached to the Chinese ethnic community in Indonesia which is strongly influenced by the stereotypes circulating among indigenous people. The general picture of ethnic Chinese in Indonesia that has existed so far is the stigma that Chinese people are "economic animals" who are opportunistic, do not have political loyalty and only think of their own interests [2]. The myths about Indonesian characters of Chinese descent are still firmly planted in our society, perhaps even in the consciousness of the Indonesian people of Chinese descent themselves. Many pressures on ethnic Chinese citizens who come from prejudice that they are economically strong, are not loyal to Indonesia and are ready to migrate to any country that offers them economic benefits. 
But even so, the inherent stigma is generally reflected in the reality in Indonesia. This is seen in the large number of Chinese people who control the economic sector and trade wherever they are. As noted by Fujitsu Research in Tokyo [3] who looked at a list of companies in 6 (six) key countries in Asia, it illustrated how the majority of the companies were controlled by overseas ethnic Chinese, for example, Thailand as many as $81 \%$, Singapore as much as $81 \%$ in Indonesia as much as $73 \%$ and others. This picture proves how much influence the role of the Chinese economy in the economy in Indonesia.

However, a different phenomenon can be seen in the profile of Chinese people in Bangka Belitung. There are striking differences between ethnic Chinese communities in Bangka Belitung and Chinese ethnic communities in other regions of Indonesia. The stigma attached to Chinese ethnicity in Indonesia so far, which is rich, exclusive, closed, and anti-social, seems broken and shows transformation. In Bangka Belitung, Malay and Chinese ethnic groups live side by side and siblings almost without exclusivity. Similarly, the stigma about identical rich Chinese is also not fully reflected in the socio-economic life of the ethnic Chinese community in Bangka Belitung. In fact, many Chinese ethnic groups are found with low economic levels that depend on living as mine coolies, laborers, farmers, or fishermen.

The poor Chinese phenomenon in Bangka Belitung cannot be separated from the history of ethnic arrivals on the islands of Bangka and Belitung. This is of course related to the arrival of Chinese in Bangka in the early 18th century who were brought in to work as mine coolers at that time. In 1750, a wave of tin workers was imported from China through a person known as Un Asing. These workers from China generally come from Guangdong who have technical capabilities by way of flowing. A report from the Dutch commissioner in Palembang in 1755 cited by Heidhues in Ibrahim [4] states that the majority of the fabriqueurs at that time were poor Chinese.

This study tries to discuss objectively the socio-economic transformation of Chinese people in Bangka, from stigma to reality. This study tries to describe and discuss objectively how the general appearance of the socio-economic conditions of ethnic Chinese communities in Bangka, with the hope of also being able to also provide a different perspective on the existence of Chinese society in controversial narratives from the Chinese stigma that are rich, exclusive, dominant, to reality Chinese people who have been acculturated in the life of the inclusion of modern society interact with each other in an atmosphere of equality or egalitarianism with other community groups.

\section{Literature Review and Research Focus}

One study related to poor Chinese social phenomena in Bangka Belitung has been conducted in Trubus Village, Lubuk Besar District, Central Bangka. Research conducted by Yodha Tony [5] found that there are at least two forms of poverty in Chinese communities in Trubus Village, namely forms of cultural poverty and natural forms of poverty. The form of cultural poverty is experienced by Chinese people who are still young, because they always rely on their work to become day laborers and natural forms of poverty are experienced by Chinese people who are old, because they are physically weak in doing their jobs because of the aging age. Meanwhile, the factors that caused poverty in the Chinese community in Trubus Village were the low level of education in the Chinese community in Trubus Village, the geographical location of the area, the absence of special skills, and limited capital that made it difficult for the community to open up jobs for themselves. 
Poor Chinese people in Bangka, mostly work as fishermen. Regarding his own poverty, Endang Retnowati [6] has examined the condition of Indonesian fishermen in a structural poverty vortex. His research found that the causes of fishing poverty in Indonesia are very complex, individual, family, sub-cultural, agency and structural causes are interrelated. Quoting the opinion of Kusnadi, Retnowati revealed several factors that caused poverty to fishermen as follows:

a. the absence of integrated policies, strategies and implementation of coastal area development programs and fishing communities among development stakeholders.

b. there is an inconsistency in the quantity of production (catch), so that the sustainability of fisheries socio-economic activities in fishing villages is disrupted. This is due to the condition of fisheries resources that have reached the condition of "over fishing", a prolonged bad season, and an increase in the price of fuel oil (BBM).

c. the problem is the geographical isolation of fishing villages, making it difficult to get in and out of the flow of goods, services, capital, and humans, which disrupts socio-economic mobility.

d. limited business capital or investment capital, making it difficult for fishermen to increase their fisheries economic activities.

e. the existence of socio-economic relations that are "exploitative" with boat owners, intermediary traders (middlemen), or fisheries entrepreneurs in the lives of fishing communities.

f. the low level of income of fishermen households, which has a negative impact on efforts to increase business scale and improve their quality.

She then explained that the main problem of fishermen's poverty was caused by the lack of capital owned and the education of fishermen who were still low (on average elementary school), and some of them did not graduate, so their ability or cognition was very limited. Their lives are also limited, the lives of fishermen are full of pressure from capital owners (boat owners and middlemen), the dependence between investors and fishermen that continues to be perpetuated (clientalism), policies and programs that are less targeted and sectoral, and also caused by the extravagant culture or living habits of fishermen, whenever their fishing income is large then usually spent immediately, lack of awareness to save or save money.

\section{Methodology}

This study was designed using qualitative design. Qualitative studies were chosen with consideration because they emphasized the concept of 'experience' as expressed by Chadwik [7] as the best way to understand social behavior. The experience in question is understood in the context that is directly related to the object of study, namely the Chinese ethnic community related to the dynamics of lifestyle, patterns of relationships and all situations in the research locus which are considered to be directly correlated with the object of study. Marsh \& Stoker [8] also stated that qualitative studies allow researchers to explore the subjective experience of a person or group of people and explore the meanings related to these experiences.

The data in this study come from several sources, namely, documents, record archives, interview transcription, direct observation, participatory observation, and other physical devices. Interviews conducted with figures or informants who are known, both directly and indirectly, become part of or intersect with the lives of poor Chinese people. Observations were made directly on the activities and relations between residents at the research locus 
which were considered easier to find the social dynamics of Chinese ethnic life. In this study researchers conducted observations in Bangka Regency in villages that were known for a long time as centers of the majority of ethnic Chinese, namely Rebo Village, Deniang Village, and Merawang Village.

The data analysis technique is carried out in four important stages, namely preparation, data collection, interpretation and presentation of data, finally the conclusion. The preparation phase is done by compiling work mechanisms such as problem formulation, theoretical framework, methods, and so on. Data collection is done with three main methods, namely interviews, participatory observation, and documentation. The next process is the interpretation and presentation of structured data. As suggested by Miles \& Huberman [7] the final step of qualitative analysis is done by determining the meaning of the data presented.

\section{Result and Discussion}

\subsection{Historiography of the Origin of Socio-Culture-Economies of Chinese Migrants in Bangka}

In the context of the Bangka Belitung, the history of the arrival of Chinese people on Bangka Island is inseparable from the history of the discovery of tin on Bangka Island. According to Reid in Ibrahim [4] tin on Bangka Island was discovered in 1710 by Chinese Muslims from Malaysia. Tin was originally done in a simple way and the Palembang Sultanate entered into a contract of sale and purchase of tin with a Dutch company, Verenigde Oostindische Compagnie (VOC) in 1722. In 1750, a wave of tin workers was imported from China through a person known as Foreign Un. These workers from China generally come from Guangdong who have technical capabilities by way of flowing. A report from the Dutch commissioner in Palembang in 1755 cited by Heidhues [4] states that the majority of the miners (fabriqueurs) that existed at that time were poor Chinese.

Reportedly there were around 6,000 tin mining workers from China in the 1770s and the majority were Hakka people. They are coordinated in a congress-gongsi-kwung sze and there is a head who is responsible for every 30 workers called Tiko or old brothers. Bangka Island at that time, as said by Heidhues, has always been associated with Chinese technology, Chinese organizations, and ethnic Chinese workers who produce and manage tin Bangka islands. Not surprisingly, in 1905, out of 115 thousand residents of Bangka Island, 43 thousand of them were Chinese, the rest were foreign and indigenous Asian groups. Meanwhile, the 1920 census showed that the Chinese population in that year reached $44.6 \%$ and this figure increased to $47 \%$ in 1930 even though the number of miners had decreased [4]. The majority of Chinese in the 1900s worked in the mining sector as laborers. Thus it became clear that the relationship of the history of the migration of Chinese people on Bangka Island with a history of fortune became very strong.

\subsection{Profile of the Bangka Belitung Chinese Community at the Study Site}

The Chinese ethnic community cannot be called as a homogeneous group. According to Hoon in Ibrahim [9], enthusiasm in Medan for example, is different from Chinese in Jakarta, Kalimantan, Bangka, Semarang, Sukabumi, Malang, and so on. Even though there are many perceptions that say that Chinese people are always rich, the poor Chinese aggregates at the 
study location, namely the Bangka Belitung Islands Province, actually show their antithetic phenomenon. Given the relatively high population, which is in the range of $8 \%$ of the entire population of the province, with a limited and distributed profile of resources in the ownership pyramid, it can be assumed that economic control will only spread to a small part.

Then what about the other large numbers? Referring to the history of migration and the composition of ethnic Chinese to Bangka, the majority as coolies or classes of the poor, it can be assumed that there was no massive and elitist transformation in both social and economic circles. What happened was assimilation and acculturation between the migrant Chinese community and local residents dynamically. This can be seen from the many marriages between Chinese people and Malays in various regions on Bangka Island. Reaffirmed by the domicile pattern that is not exclusively exclusive or isolated. In Bangka and Belitung can be easily found by poor Chinese people in the list of recipients of assistance from the government, whether assistance in the context of social safety nets such as Rastra, BPJS PBI, KIP, etc., as well as assistance to efforts to improve the economy such as seedlings, seeds , KUBE, Farmer groups, and so on.

Social interaction is a dynamic relationship, involving reciprocal relationships between individuals and individuals, groups with groups, and between individuals and groups. Interactions that occur in each group that have status, role, social, economic conditions and education level will vary. This interaction can be in the form of cooperation, competition, conflict and conflict. Based on observations and interviews, the community in general is in a very harmonious social environment even though its configuration is dominated by the culture and atmosphere of Chinese culture. The atmosphere of the environment and social relations that are very comfortable among fellow citizens is a determinant factor of the reasons why citizens like the social conditions that are interwoven and take place in this region. Domicile which is also relatively close to the workplace also makes the surrounding community consider the present place of residence pleasant.

Table 1. Number of people and its ethnic in 3 study areas.

\begin{tabular}{ccccc}
\hline Ethnic & Rebo & Merawang & Deniang & $\begin{array}{c}\text { Percentage } \\
\text { average }\end{array}$ \\
\hline Malay & 1.587 & 234 & 499 & 24,00 \\
Javanese & 115 & 457 & 99 & 2,46 \\
Chinese & 2.673 & 1.817 & 1.562 & 48,73 \\
Bangkanese & 1.625 & 172 & 250 & 21,58 \\
Other & 73 & 90 & 207 & 3,22 \\
Ammount & 6.073 & 2.770 & 2.617 & 8.690 \\
\hline
\end{tabular}

\subsection{General Description of Chinese Ethnic Poverty in Bangka}

Referring to the theoretical framework, to describe the forms of poverty experienced by Chinese citizens in this study can be done by describing how the pattern of fulfilling minimum needs in general. The first aspect was found in almost all poor Chinese citizens meeting their daily nutritional needs depending on availability with ingredients in the surrounding environment. They process their own simple food items such as vegetables or proteins from the results of land and marine catches that are obtained by themselves or by buying cheaply or even given by neighboring fishermen. Although it seems simple, it is rarely found in this circle of people who suffer from eating disorders. The average citizen who the researchers met, 
especially the parents, still seemed relatively fit and healthy despite claiming that the food menu had been simple and not varied since a long time ago.

In terms of boards or housing, poor Chinese citizens have their own dynamics. First in terms of models and building materials. The researchers found several houses that were classified as poor with permanent and magnificent buildings, but only inherited from their ancestors who were still well cared for. But still most of them are in the form of very simple buildings. Many houses are found only made of wood and with a roof of zinc, some houses are covered with cement floors, but not a few houses are made of 'jerjak' wooden walls (small wood with a diameter of approximately $2 \mathrm{~cm}$ ) with an erect and only floor structure with a size very small area. Some inhabited a large family of 3 generations with furniture that was even very traditional, old-fashioned, and old. Some houses that are not habitable have indeed received assistance from the government and state and private companies to be rehabilitated.

What's interesting about the Bangka ethnic Chinese settlements is the distribution of its own domicile with a long distance from one house to another. In contrast to the characteristics of Malay villages that gather along highways or streams, the Chinese people just live to spread to remote areas separately with a distance between neighbors. Both the middle class and the poor do this pattern. Based on the experience of researchers exploring a number of villages in the study area, residents' houses were found to spread into areas that were not uncommon such as in forests, to the foothills and coastal areas. There are many rats found with various village activities in general. This phenomenon of living in seclusion was explained by an elderly informant in Rebo Village. Lie Sun Kit (83 years old) for example stated as follows:

"This is indeed the pattern of our residence of Chinese citizens whose original ancestors

were farmers. The most important thing is to have large land and live more peacefully.

Not rushed (chased) by the government as before. All needs are met by very high results.

Some non-existent needs can occasionally buy or exchange with neighbors. Just living enough, you should not be greedy because it will ruin life itself "

Mita Kasim, Head of the Planning Office Rebo Village Government gave an affirmation of the condition of the villages of the poor in his village.

"We cannot equate Chinese people who are here with Chinese people in Jakarta. Here are a lot of poor people. You have seen many houses in remote areas and made of wood, right? They are usually farmers, small fishermen, or day laborers. Like that, sir, they live to an adequate standard and don't vary. So we classify poor, low income, but enough for everyday. Some of them we put in the recipient community of Raskin (poor rice), even though it is still lacking, because many hope and deserve help too."

The conditions of settlement of Chinese people who live spread and are remote in remote areas of the forest can be explained historically. In the past, Chinese people migrated to forest areas mostly because they had fled from mines or trenches belonging to the colonial government, then worked as plantation laborers belonging to indigenous people, became tin laborers with pribumi, or built new lives in inland forests.

Because of this, the Dutch then made a regulation that obliged residents to build houses and have more activities in settlements built along highways in Bangka. The aim was to tighten Dutch control over the exploitation and trade of important Bangka commodities, especially Tin and Pepper and counteract the smuggling of Tin and Pepper which was rampant and detrimental to the Dutch at that time. However, for Chinese people who have been comfortable living safely in the interior, they still maintain this lifestyle, even today. The impact is that on average they currently have houses with very large yards (up to 1 acres) which are also used as gardening areas or raising their own livestock. Even this remoteness is often a support for those who run dark businesses or other survival reasons. 
Regarding the need for health services, according to informants' confession, it is actually not too difficult to reach and fulfill. But the lifestyle that is applied is sometimes out of sync with health modernism. The conventional life that these Chinese people lived in had an impact on the rarity of popular diseases nowadays and many of them were long-lived healthy and fit. If there is illness, healing efforts are more traditionally carried out by the dukun or commonly known as 'Taipak'. However, Head of Rebo, Fendi S.H stated that the government's efforts to pay attention to the welfare of its citizens have been quite optimal even though they have not been able to cover everyone. BPJS services whose contributions are borne by the government have covered many poor people in their area. Yuliarno, Head of Deniang, also stated that much assistance was channeled to the poor. The source is from mutual cooperation, from the results of the business unit fees run in the village, as well as assistance flowing from outside non-governmental parties.

Regarding the fulfillment of education needs, it is indeed one of the fundamental problems faced by poor people, not least among poor Chinese people in Bangka. Desi, Merawang Village Secretary as well as the Merawang Village youth figure stated the complicated problem as follows:

"Many have dropped out of school because they have to work. Schools are also far away so the costs are expensive, most Chinese here are Chinese gardens, their income is small. If there is someone who is rich from the business, it is more because indeed the trade mentality and perseverance take care of the business from zero. When there are Unconventional (TI) Mines, those who are in schools also prefer to go to work. Very few young people get to college, especially those who come out of Bangka."

Nam Kwet, a youth figure from Rebo Village also expressed the same opinion:

"Education is rather low. It also depends on the economy of the family, on average the poor families do not prioritize their children's school. Just enough education, until junior high school or vocational school is very extraordinary. Besides that, there is still a low awareness of education, schools for most citizens are quite good at reading and writing, after all, they are still workers or entrepreneurship. Many residents feel comfortable with their lives here. So that only a handful of young people who try their luck wander well to work looking for experience outside the region and those who continue their higher education."

\subsection{Identification of Factors Causing Chinese Ethnic Poverty in Bangka}

\subsubsection{Structural Aspect}

The poverty condition of the ethnic Chinese community in Bangka is motivated by structural conditions, where competitiveness and regional economic conditions make it difficult for them to survive in the midst of a very heterogeneous and competitive climate. In Merawang this is no longer dominated by ethnic Chinese. Many immigrants, mainly from Javanese and Madurese ethnic groups, have lived to blend in with the old population. the residents here live with tolerance and work together without any conflict with SARA. Usually in the tin mining sector which some time ago was excellent. Now that tin is running out, jobs are difficult, so many are unemployed. In an indigineous condition, competitiveness and economic conditions in the region give depth impact for the weakness of Chinese people's economic capacity and capability. 


\subsubsection{Cultural Aspect}

The poverty condition of Chinese people in Bangka is caused by cultural factors, where the pattern of livelihood of Chinese people is mostly fishermen, farmers, and small farmers. And such work has been going on for generations from generation to generation. This is what ultimately causes the ethnic Chinese community in Bangka to get out of poverty.

Culturally, indeed there are no customs or habits that are successful (rich) in supporting small ones in business like the Minang people for example. There is pure competition and struggle of each. So it is not surprising, if the striking difference between the rich and the poor fellow Chinese here looks very obvious. But that does not mean not helping each other or helping. In social matters it is still like other societies in general.

"In this area of Rebo from generation to generation, the income from the plantation sector is true, there are those who plant pepper, there are also those whose income is from selling coconuts, chocolates, key oranges, and growing vegetables. For oil palm, usually have a big boss, people here are only paid to take care of it. Many also raise pigs or chickens for extra. But, raising pigs is also not cheap, the cost of treatment, eating a lot, so only certain people too, or even maintaining but not much, around 2 to 4 only, and their children are sold to large farmers. The most work is also as fishermen, and it has been passed down for generations. (Interview with Mita Kasim)

\subsubsection{Access to ownership and control of resources and production factors}

The economic conditions of the ethnic Chinese community in Bangka are strongly influenced by factors of ownership and control of resources and factors of production. Those who own land usually live more prosperously. As if there is a correlation between land ownership and the level of community welfare. The greater the land ownership, the more prosperous it will be.

"In our area land ownership is indeed one of the determinants of welfare. Having large land means more gardening, or in the last era if the land contained tin content, it could mine alone or take fees from people who wanted to mine on their land. This opportunity brings many blessings to some residents. With IT, they can improve their homes or gardening on other fields. But not all have large land, those who do not have land usually work as casual daily laborers, work in Unconventional Mines (TI), or garden/farm small for daily income. "

\subsection{Factors Causing Poverty in Chinese Ethnic Communities in Bangka}

The poverty condition of Chinese people in Bangka is caused by several factors. First, the historiological factor of Chinese ethnic arrivals to Bangka. The wave of Chinese ethnic migration to Bangka in order to become a tin mining worker / laborer was the initial answer in answering the question of why the ethnic Chinese in Bangka were far from the stigma of being rich and exclusive. This happened because indeed the ethnic Chinese people who came to Bangka were poor Chinese in their original place and migrated to become unskilled laborers to Bangka Island. In the theory of poverty proposed by Baswir and Sumodiningrat in Setiadi [10], this condition is categorized as natural poverty, namely the condition of poverty because from the beginning it was already poor. Although the ethnic Chinese life in Bangka has been running for hundreds of years from generation to generation, not much has changed in the economic life of the ethnic Chinese in Bangka, because the factors that caused poverty in the ethnic Chinese in Bangka were not only natural factors, but also perpetuated by cultural and structural factors. 
Second, cultural factors. Cultural poverty refers to the lifestyles, habits and culture of Chinese ethnic communities in Bangka who tend to be reluctant to improve or change their lives because they have felt enough with their existing lives. This characteristic condition is a manifestation of the characteristic transformation of Chinese people who have been stigmatized by opportunists, animal economics, money oriented, hard-working and not easily satisfied to be satisfied and calm enough with what they already have and the life they live.

Third, structural factors. Structural factors also contributed to the poverty of ethnic Chinese people in Bangka increasingly lasting from generation to generation where economic policies and order in Indonesia tended to favor indigenous groups rather than Chinese. In the end, the structural and cultural conditions of poor parents caused the ethnic Chinese children in the next generation to be powerless and limited in access to education which ultimately caused the poverty chain to be difficult to release, except for Chinese people who decided to migrate and be able to lucky to be successful overseas, the number is not small.

\subsection{Transformation of Socio-Economic Ethnic Chinese Communities}

It can almost be said that in fact there has not been a shift in the socio-economic status of the Tinghoa ethnic community in Bangka on a massive scale since the arrival of their ancestors until now. Because in reality, the socio-economic conditions of poor Chinese people had indeed been poor already since their first arrival to Bangka Island from mainland China. This condition continues because it is trapped in the structural and cultural conditions of their lives in Bangka, which causes poverty to continue to this day.

The lives of ethnic Chinese in Bangka that have been going on for decades, even hundreds of years of generations on the island of Bangka have caused them to be assimilated and culturally well-versed in their interactions with indigenous peoples [11]. Even not only socio-economically, in terms of characteristics and culture, they are far from the characteristics and culture of Chinese people in China mainland who are closely stigmatized as rich, exclusive, opportunist, money oriented, hard-worker, and not easily satisfied with their achievement [12].

Chinese people in Bangka have similar characteristics to indigenous people. They tend to feel quite satisfied with the life they live as they are and are not adventurous. This is ultimately the answer to the conditions of the Chinese people who remain stagnant with their poverty. In addition to the historical factors of early arrival migration, structural factors, and cultural factors, their narrow mindset factors also contribute to their perpetual poverty from generation to generation.

Thus it can be said that the real transformation does not occur in the factual conditions of the Chinese ethnic community. An interesting finding is the slack at the level of stigma over the reality that surrounds it. Groups/communities that have stigmatized have experienced a migration of understanding of the initial stigma that is believed to a new understanding encountered in the factual conditions of Chinese people in Bangka. The stigma that has emerged among the Indonesian people so far has impressed a simplification of Chinese as a homogeneous ethnicity. Even though it's not the way it should be. according to Hoon in Ibrahim [9], enthusiasm in Medan is different from Chinese in Jakarta, Singkawang, Bangka, Semarang, Sukabumi, Malang, and so on. Even though many perceptions say that Chinese people are rich, they cannot be denied the fact that many Chinese people are poor in Tangerang, Pontianak, and the Riau Islands. Hoon uses the terms regionality and class as two important parts which are factors in the heterogeneity of Chinese identity. What is also a 
feature of Chinese existence in Indonesia according to Lim \& Gosling in Ibrahim [9] that the distribution tends to be evenly distributed, not clustered in big cities, as happened in Bangkok.

Chinese heterogeneity thus becomes an inseparable color. They are heterogeneous in terms of religion, culture, language, regional origin, class, and patriarchal system. This is a primodial fact that cannot be denied. That they are Chinese with certain characteristics and that they are Chinese with distinguishing features that are easily identified.

\section{Conclusion}

The life of the Tinghoa ethnic community in Bangka is quite different from the stigma inherent so far; rich, exclusive, opportunist, and money oriented. The factual condition of the Chinese ethnic community shows a simple life and almost no noticeable difference with indigenous people (ethnic Malays) in terms of social and economic life. Tinghoa and indigenous (ethnic Malays) ethnic communities live in harmony, without a barrier, without ravines. This is due to conditions between the two ethnic groups that are socially and economically equal. In fact, not a few Chinese people live with low / poor economies.

The factors that cause poverty in Chinese people are caused by several factors, namely; historical factors of the early arrival of Tinghoa ethnic to Bangka who were already poor and came as unskilled workers (tin miners), added structural and cultural factors which led to the persistence of Chinese ethnic poverty from generation to generation, and the mindset of Chinese people in Bangka has undergone a transformation from its ancestors mindset which tends to be opportunistic, money oriented, and not easily satisfied. The accumulation of these factors ultimately makes Chinese people in Bangka currently stagnant with the existing conditions. Very little and difficult for poor Chinese people to escape the poverty chain. And that has been going on for decades and even hundreds of generations.

\section{Acknowledgments}

The authors would like to say thank you for One Asia Foundation that supports us with the grants, Dean of Faculty of Social and Political Science, and other people whose contribution encourage us to finish this research.

\section{References}

[1] Idi, A.: Asimilasi Cina dan Melayu di Bangka. Tiara Wacana. (2009)

[2] Kwartanada, D.: Minoritas Cina dan Fasisme Jepang: Jawa, 1942-1945. Kanisius dan Lembaga Studi Realino. (1999)

[3] Naisbitt, J.: Megatrends Asia. Touchstone Rockefeller Center, New York. (1997)

[4] Ibrahim: The Bussines Politics of Chinese Ethnic in Bangka Belitung on Post New Order. Journal of Government and Politics, Volume 6, No. 1. (2015)

[5] Tony, Y.J.: Chinese Poor Social Phenomenon in Trubus Vilage Middle Bangka Regency. Sosiology Department FISIP UBB, Thesis. (2017)

[6] Retnowati, E.: Indonesian Fisherman in the Structural Poverty Involution (Social, economic, and Law Perspective). Journal PERSPEKTIF Mei Edition Vol. XVI No. 3 (2011) 
[7] Huberman, M.A. and Mattew M.B.: Data Management and Analysis Method in Handbook of Qualitative Research. Editor by Norman K. Denzin dan Yvonna S. Lincoln, Pustaka Pelajar, Yogyakarta. (2009)

[8] Marsh, D. and Gerry S.: Theory and Method in Political Sciences. Nusa Media. (2010)

[9] Ibrahim.: Business, Power, and Identity (A Political Behaviour Study of Chinese Ethnic in Bangka Belitung Post-New Order). Disertation, Gadjah Mada University. (2015)

[10] Setiadi, E.M. \& Kolip, U.: Introduction to Sociology. Prenadamedia Group. (2011)

[11] Erman, E.: From the Formed of Kampung to the Dark Matter, Uncover the Bangka Belitung Tin Mining History. Ombak Publishing. (2009)

[12] Darini, R.: State Policy and Anti-China Sentiment: Historical Perspective. Thesis, Yogyakarta National University. (2012) 